\title{
As relações plásticas e narrativas em um livro infantil acessível a deficientes visuais: uma abordagem semiótica
}

The plastic and narrative relations in a children's book accessible to the visually impaired: a semiotic approach

TAVARES, Carolina Savioli Marques; Bel.; UDESC Mestranda PPGDesign

carol.tavares.itu@gmail.com

QUIQUIO, Rodrigo Lago; Bel.; UDESC

rodrigo.lago.quiquio@gmail.com

BOGO, Marc Barreto; Me.; UDESC / Doutorando PUC-SP: COS/CPS e UNILIM: CeRes

marcbbogo@gmail.com.br

\section{Resumo}

Considerando a importância da acessibilidade para pessoas com deficiência visual desde a infância, o presente artigo vale-se do percurso gerativo de sentido da semiótica discursiva para entender a construção de sentido no livro infantil "Adélia Sonhadora", da Coleção Adélia, acessível a crianças com deficiência visual. Composto por diversas linguagens, como a verbal escrita, visual, tátil e olfativa, vê-se na semiótica uma oportunidade metodológica para analisar este material sincrético e contribuir para o desenvolvimento de futuros livros infantis acessíveis. Após a apresentação do objeto de estudo, é analisado o plano do conteúdo em seus três níveis (discursivo, narrativo e fundamental), encontrando a possível oposição semântica de /real/ versus /imaginário/, tanto na narrativa da personagem quanto no percurso feito pelo leitor. Também é estudado o plano da expressão do texto através da semiótica plástica, observando como suas categorias se relacionam com o plano do conteúdo.

Palavras Chave: livro infantil, acessibilidade, semiótica discursiva, Adélia Sonhadora.

\section{Abstract}

Considering the importance of accessibility for people with visual impairments since childhood, this paper applies the generative process of meaning from the discursive semiotic to understand the construction of meaning in the children's book "Adélia Sonhadora", from the Collection Adélia, accessible to visually impaired children. Composed by several semiotic systems, such as verbal writing, visual, tactile and olfactory, the semiotics is a methodological opportunity to analyze this syncretic material and contribute to future accessible children's books. After the presentation of the object of study, the plan of content is analyzed by the three levels of its course (discursive, narrative and fundamental), discovering the possible semantic opposition /real/versus /imaginary/, both in the narrative of the character and in the course made by the reader. The plan of expression is also analysed through the plastic semiotic, observing how its categories relate to the plan of content.

Keywords: children's book, accessibility, discursive semiotic, Adélia Sonhadora. 


\section{Introdução}

Conforme censo demográfico do Instituto Brasileiro de Geografia e Estatística (IBGE), aproximadamente 45 milhões de pessoas, ou $23,9 \%$ da população brasileira declararam ter, em 2010, uma das deficiências por eles analisadas (visual, auditiva, motora, mental ou intelectual), das quais 7,5\% são crianças de 0 a 14 anos de idade. Considerando o Design Inclusivo, é necessário o desenvolvimento de materiais que fomentem a inclusão social deste público infantil, de modo a conscientizar futuras gerações acerca da relevância da acessibilidade e possibilitar a integração entre todas as crianças, tanto no ambiente escolar quanto fora dele, em momentos de lazer e estimulação cultural.

A deficiência visual atinge de 6,5 milhões de pessoas no Brasil, sendo mais de 500 mil destes incapazes de enxergar, enquanto os demais possuem baixa visão. Outras 29 milhões de pessoas declararam, ainda, ter alguma dificuldade para enxergar, fazendo uso de óculos ou lentes corretoras (IGBE, 2010). Segundo artigo da Fundação Dorina Nowill para Cegos, "a deficiência visual é definida como a perda total ou parcial, congênita ou adquirida, da visão". Divide-se em dois grupos: cegueira, na qual há perda total da visão ou pouca capacidade de enxergar, sendo necessária a leitura pelo Sistema Braille; e baixa visão, na qual a pessoa apresenta $30 \%$ ou menos de visão no melhor olho, sendo possível ler textos impressos ampliados ou com alto contraste.

Ao considerar a concepção de materiais culturais e educacionais, como livros literários, compreende-se a importância da combinação entre elementos que permitam a total compreensão de seu conteúdo a pessoas com deficiência, com destaque às ilustrações, mantendo-se atrativo e lúdico. Para Van der Linden (2011, p.157) "o livro ilustrado é uma forma original, livre e que, felizmente, permanece em parte inapreensível". Como objeto complexo, os livros ilustrados voltados ao público infantil possuem técnicas variadas, envolvendo a experiência sensorial do livro na relação livro-leitor. Nestes materiais, aplicam-se elementos como as cores, tamanho, estilo de fonte, ilustrações e tipos de impressão, mas a conceituação pode ir além ao considerar fatores de acessibilidade.

Observa-se, portanto, dificuldade em encontrar materiais ilustrados acessíveis a pessoas com deficiência visual. Afinal, as ilustrações podem ser sentidas, exploradas e descritas a este público que, embora apresentem disfunções na visão, interagem pelos demais sentidos e se expressam ao mundo por outras linguagens. Este artigo busca compreender a construção de sentido presente no livro acessível a crianças com deficiência visual "Adélia Sonhadora", que combina diversos elementos sensoriais com o Braille. A seguir, no intuito de explicitar o aparato teóricometodológico da Semiótica adotado, serão apresentados os níveis do percurso gerativo de sentido e, posteriormente, o plano da expressão, apresentando as observações realizadas a partir do texto analisado e resultando na discussão acerca das relações entre conteúdo e expressão neste objeto.

\section{Objeto de estudo e contextualização teórica}

A presente pesquisa pretende analisar a narrativa e o sincretismo no livro infantil "Adélia Sonhadora", que se apresenta como importante objeto na mídia impressa atual ao permitir a leitura compartilhada de pessoas com ou sem deficiência visual através da combinação de diversas linguagens e da exploração sensorial. O livro, voltado à faixa etária de 3 a 10 anos, inclui pessoas 
com grau de limitação visual de 10 a 100\%. Desenvolvido pela designer Wanda Gomes, que utilizou do design gráfico como ferramenta para a acessibilidade cultural e educacional, seu texto foi escrito por Lia Zatz e ilustrado por Luise Weiss, segundo dados da WG Produto. É o terceiro livro da Coleção Adélia que, incluindo os livros "Adélia Cozinheira" e "Adélia Esquecida", aborda temas infantis diários acerca das tarefas, relacionamentos e desenvolvimento da autonomia.

Os elementos gráficos do livro são aplicados para aguçar três aspectos da percepção humana: visual, tátil e olfativo. O livro infantil tem texto em braille e em escrita alfabética, possibilitando a leitura de pessoas com ou sem deficiência visual, além de aromas, texturas, relevos e cores, que estimulam um entendimento multissensorial do material. Assim, há maior interação entre o leitor e o livro, convidando as crianças à experimentação dos sentidos. A coleção inova ao aplicar o Braille.BR ${ }^{\circledast}$, idealizado por Wanda Gomes, que permite a leitura por pessoas com deficiência visual ou visão normal. De acordo com a WG Produto, esta impressão em braille não amassa o papel, sendo composto por camadas de verniz que garantem a transparência. É possível também imprimir em ambos os lados do papel, podendo ser impresso em papéis de gramaturas mais leves e resultando em livros com menor volume.

Este objeto de estudo se torna relevante para o design inclusivo pela maneira em que os elementos gráficos foram aplicados e conectados com a narrativa do texto, de forma a serem entendidos por crianças videntes ou com deficiência visual, seja ela total ou parcial, alfabetizadas ou não. O design inclusivo pode "ser definido como o desenvolvimento de produtos e de ambientes, que permitam a utilização por pessoas de todas as capacidades" (SIMÕES e BISPO, p.08), não limitando-se, portanto, a somente atender as necessidades de pessoas com deficiência, mas sim de ser acessível a toda população e incentivar a inclusão social. Tais elementos que contribuem para a acessibilidade estão diretamente atrelados à narrativa do texto, a história de Adélia que, neste livro, decide brincar ao imaginar que está em um castelo e reunir diversos objetos que representam as personagens por ela inventadas.

Imagem 1 - Capa e página dupla do livro "Adélia Sonhadora".

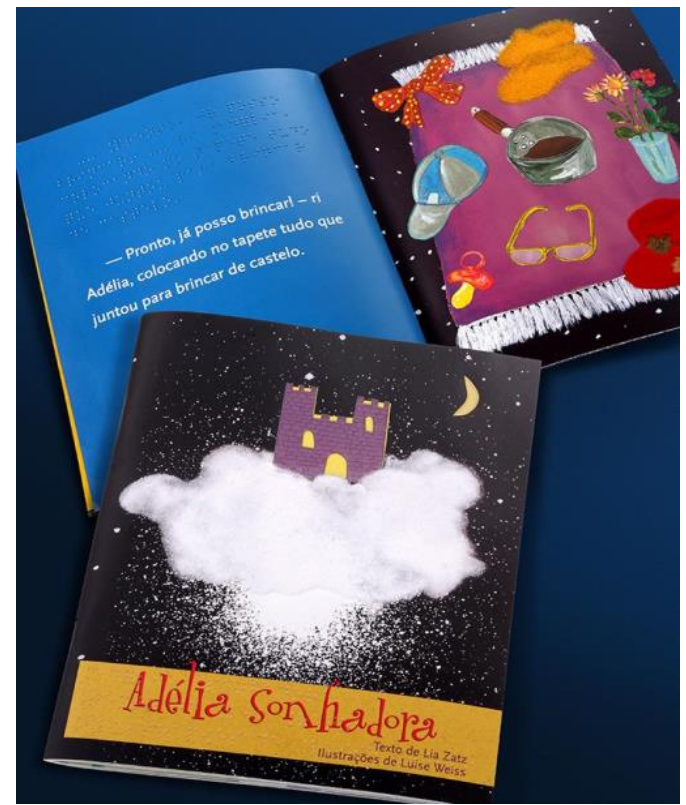

Fonte: https://www.wgproduto.com.br. Acesso em 18 de março de 2018. 
Este estudo apropria-se metodologicamente da semiótica discursiva, também conhecida como greimasiana ou francesa que, tendo suas origens na obra de A. J. Greimas, possibilita o estudo dos sentidos, das composições e dos sistemas de organizações para investigação de textos, sendo estes os mais diversos objetos que se estruturam em um todo de sentido. Desta forma, a análise do livro é composta de duas etapas: primeiramente é realizado um estudo sobre o plano do onteúdo, utilizando-se do percurso gerativo de sentido e, posteriormente, são apontadas as categorias plásticas do corpus estudado, compreendido no plano da expressão, possibilitando a total compreensão do texto apresentado. A retomada da teoria semiótica de Greimas se dá a partir de seus desdobramentos nos estudos de como Fiorin (2008) e Teixeira (2008), autores que explicitam os conceitos utilizados.

José Luiz Fiorin (2008, p.20) define o percurso gerativo de sentido como "uma sucessão de patamares, cada um dos quais suscetível de receber uma descrição adequada, que mostra como se produz e se interpreta o sentido, num processo que vai do mais simples ao mais complexo". Serão apresentados os três níveis do percurso, na seguinte ordem: discursivo, narrativo e fundamental. Para Fiorin, o nível fundamental abriga as categorias semânticas de base e fundamenta-se numa diferença, numa oposição. O nível narrativo traz "uma transformação situada entre dois estados sucessivos e diferentes" (FIORIN, 2008, p.27). Por fim, "no nível discursivo as formas abstratas do nível narrativo são revestidas de termos que lhes dão concretude" (FIORIN, 2008, p.41). O quadro exposto a seguir se refere ao percurso gerativo de sentido, apresentando os três níveis e suas dimensões sintáticas e semânticas.

Quadro 1 - Percurso Gerativo de Sentido.

\begin{tabular}{|c|c|c|}
\hline NÍVEL & SINTAXE & SEMÂNTICA \\
\hline DISCURSIVO & Relações na instância da Enunciação & $\begin{array}{l}\text { Operações de figurativização e } \\
\text { tematização }\end{array}$ \\
\hline NARRATIVO & $\begin{array}{c}\text { Percurso Narrativo (Manipulação, Competência, } \\
\text { Performance e Sanção) }\end{array}$ & $\begin{array}{l}\text { Construção dos objetos modal e } \\
\text { de valor }\end{array}$ \\
\hline FUNDAMENTAL & $\begin{array}{c}\text { Operações de negação e asserção dos termos da } \\
\text { semântica fundamental }\end{array}$ & Oposição semântica de base \\
\hline
\end{tabular}

Fonte: Fiorin (2002), adaptado pelos autores (2018).

Em paralelo ao plano do conteúdo, o plano da expressão observa como o conteúdo do texto está relacionado à materialidade plástica por ele apresentado e como tais características importam na geração do sentido. A semiótica plástica analisa o texto a partir de quatro categorias: cromática (cor), eidética (forma), topológica (distribuição) e matéria (materialidade).

A partir deste objeto e da teoria apresentada, inicia-se a investigação acerca das conexões entre conteúdo e expressão, de modo a observar como a narrativa aliada aos demais recursos possibilita uma melhor experiência na leitura e, consequentemente, proporciona a leitura conjunta de crianças com e sem deficiência visual.

\section{Plano do Conteúdo}


Conforme exposto anteriormente, o nível discursivo é o mais concreto e superficial dos três níveis do percurso gerativo de sentido. Nele, analisamos a dimensão semântica, descrevendo os temas e as figuras, e a dimensão sintática, na qual são apresentados o enunciador, o enunciatário e as três instâncias da enunciação (actorialização, temporalização e espacialização).

"Adélia Sonhadora" conta a história de Adélia, uma menina que decide brincar de castelo em sua casa. Não é apresentada nenhuma característica particular ou ilustrações da personagem; ela é diretamente introduzida na primeira página e logo há uma fala. Vale ressaltar que Adélia é a única personagem atuante do livro e o narrador apenas precede e contextualiza suas falas. A narrativa se desenvolve a partir das personagens fictícias criadas por Adélia como moradores de seu castelo imaginário. No texto, a primeira personagem apresentada é a rainha, para qual Adélia diz que escolherá algum objeto para representá-la. Só é possível descobrir este objeto representante ao analisar a página ao lado direito com a ilustração. Isso faz com que o leitor desenvolva uma conexão entre os enunciados verbais e as ilustrações, uma vez que esse modelo é replicado em diversas páginas até o final do livro. O livro retrata, desta forma, temas como infância, sonho, imaginação, fábula e até mesmo realeza.

As ilustrações representam objetos do dia-a-dia que poderiam facilmente ser encontrados na casa de Adélia, como um boné, sapatos e uma panela. A personagem utiliza cada um desses instrumentos para representar um dos moradores do castelo. No caso da rainha, a página direita traz a ilustração de um chapéu vermelho com flores, ligado a figuras femininas e talvez maternas. As ilustrações não são iconográficas, elas possuem certa liberdade artística, com ângulos diferenciados, fazendo com que o leitor precise interpretar o objeto representado a partir da leitura da página anterior e das experiências prévias. Para Guto Lins (2002, p. 36), "a ilustração extremamente literal ou puramente ornamental e decorativa não representa mais a diversidade, a pluralidade e a riqueza de informações visuais a que as crianças de hoje têm acesso". A identificação do objeto também pode ser feita pelo tato e olfato, indo além da visão. Aplicando as ilustrações desta forma, as crianças são estimuladas a aprender e a interagir profundamente com o livro, uma vez que ele apresenta as informações de uma maneira criativa e não óbvia. A ilustração diferenciada é, portanto, uma importante ferramenta no desenvolvimento de repertório para o leitor infantil.

Imagem 2 - Exemplo de página dupla do livro.

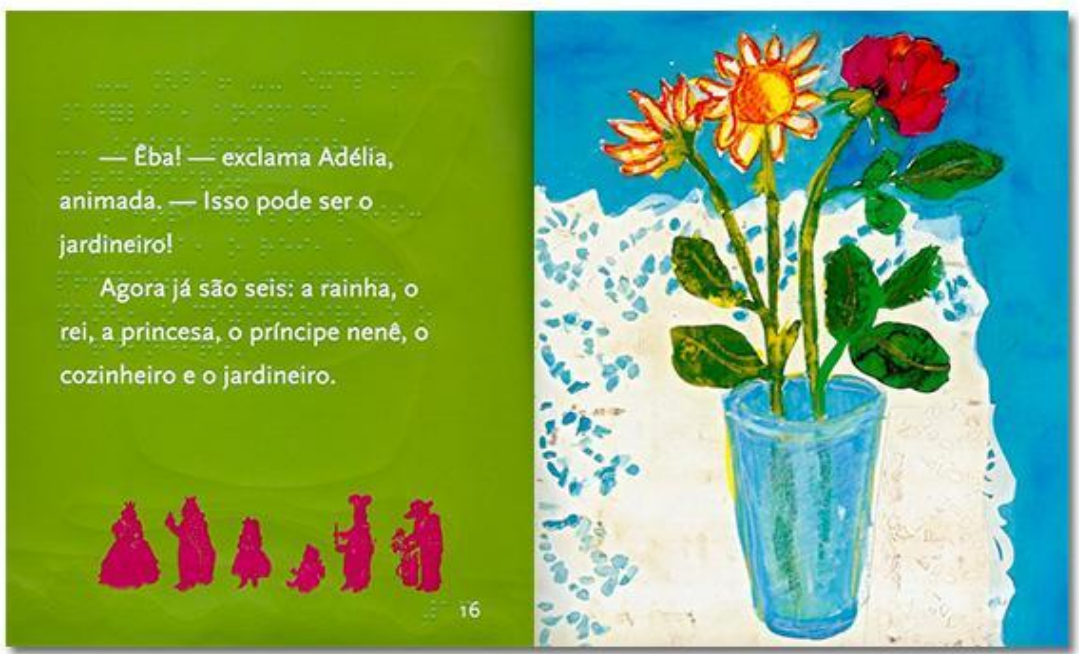


Fonte: <http://liazatz.com.br/site/livros/colecao-adelia/>. Acesso em 18 de março de 2018.

Os personagens criados por Adélia são ilustrados iconograficamente na porção inferior das páginas com texto e seguem um padrão de repetição, de forma que a cada página dupla é adicionada uma nova personagem que se conecta com o texto e a ilustração da página direita. Os ícones são contornados por verniz localizado, que pode ser sentido pelo tato, e se repetem, fazendo com que a criança se familiarize com o contorno de cada um. Cada personagem possui um detalhe que o caracteriza e facilita seu reconhecimento tátil. A rainha possui uma coroa; o rei, além da coroa, porta um orbe na mão; a princesa é representada em menor escala e com um laço na cabeça; o príncipe nenê é o menor personagem ilustrado e carrega um chocalho; o cozinheiro tem chapéu e segura colher e panela; o jardineiro, também com chapéu, manuseia plantas; a vovó sentada em uma cadeira de balanço faz tricô; e o gato, com sua forma diferenciada e rabo levantado. Para o aprendizado, as repetições, também chamadas de isotopias, são importantes para o entendimento do texto como um todo, como descreve Fiorin (2008, p. 112): "o que dá coerência semântica a um texto e o que faz dele uma unidade é a reiteração, a redundância, a repetição, a recorrência de traços semânticos ao longo do discurso".

Imagem 3 - Exemplo de página dupla do livro.

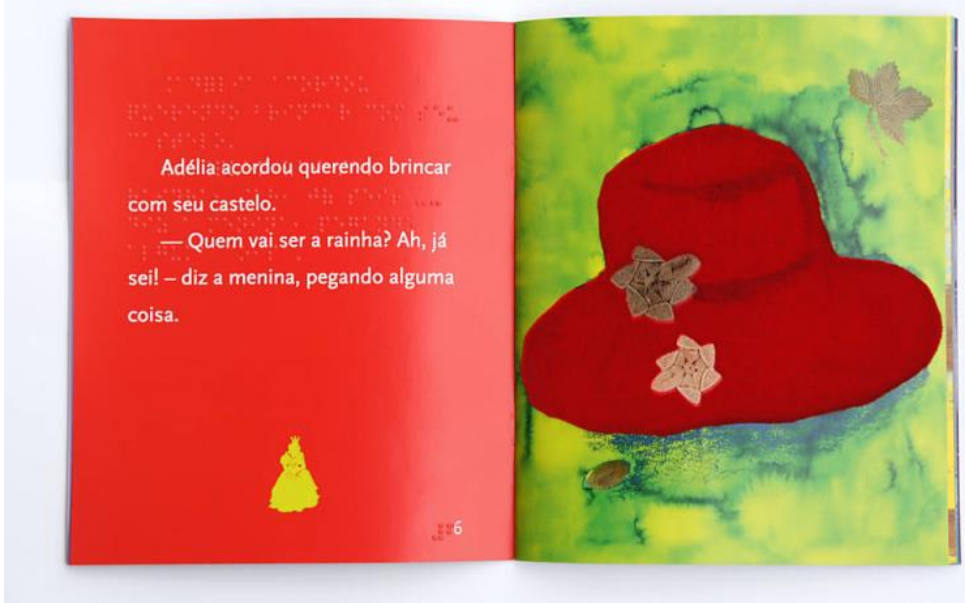

Fonte: <http://www1.folha.uol.com.br/saopaulo/1189436-adelia-sonhadora-une-boa-historia-e-ilustracoes-comtexturas-e-cheiros.shtml> Acesso em 18 de março de 2018.

Uma vez descrita a dimensão semântica, analisamos a dimensão sintática do livro, na qual podemos definir o enunciador e o enunciatário. Fiorin (2013, p.56) explica que "o enunciador e o enunciatário são o autor e o leitor. Não são o autor e o leitor reais, de carne e osso, mas o autor e o leitor implícitos, ou seja, uma imagem do autor e do leitor construída pelo texto". No livro analisado, a personagem Adélia é uma projeção do enunciador ao nos contar sua brincadeira; enquanto a imagem do leitor, possivelmente uma criança, é o enunciatário deste livro.

$\mathrm{Na}$ instância da enunciação, cabe analisar as categorias de atores, espaço e tempo, denominadas debreagens. Existem dois tipos de debreagens: as enuncivas e as enunciativas. Quando Adélia fala, se trata de uma debreagem enunciativa interna, uma vez que temos um "eu", um "aqui" e um "agora", conforme podemos observar no trecho: "- Pronto, já posso brincar!". É 
interna porque, segundo Fiorin (2008, p. 66-67), "isso ocorre quando o narrador dá a palavra a uma das pessoas do enunciado ou da enunciação já instalada no enunciado". Já quando o narrador fala, se trata de uma debreagem enunciva. É enunciva pois ele narra um acontecimento já passado por Adélia, mesmo o tempo verbal estando no presente. Este narrador busca complementar as descrições e vivências de Adélia.

Partindo para o nível narrativo, define-se que a narratividade é uma transformação situada entre dois estados sucessivos e diferentes. Isso significa que ocorre uma narrativa mínima, quando se tem um estado inicial, uma transformação e um estado final. Uma narrativa complexa estruturase em uma sequência canônica, que compreende quatro fases: a manipulação, a competência, a performance e a sanção (FIORIN, 2008).

A narrativa do livro aqui apresentado é simplificada, uma vez que a manipulação está implícita, ou seja, depreendemos que antes mesmo de termos contato com a narrativa, a personagem Adélia já foi levada a querer brincar com os objetos de sua casa. O texto inicia diretamente com a personagem na fase da competência, pois ela já possui o conhecimento de como estruturar sua brincadeira e de como separar os objetos para representar as personagens por ela criadas, passando esse "saber" ao leitor. A performance se dá quando Adélia está efetivamente pronta para brincar após coletar seus objetos, mas acaba adormecendo, passando por uma transformação. Ao adormecer, ela sonha com tudo aquilo que havia preparado para a brincadeira, só que, desta vez, ela também fazia parte do conto de fadas, chegando à sanção da narrativa.

A semântica do nível narrativo é caracterizada pelos objetos modais e objetos de valor. Segundo Fiorin (2013, p. 36-37), "os primeiros são o querer, o dever, o saber e o poder fazer, são aqueles elementos cuja aquisição é necessária para realizar a performance principal. Os segundos são os objetos com que se entra em conjunção ou disjunção na performance principal". Os objetos modais do livro são aqueles ilustrados nas páginas direitas, representando objetos do dia-a-dia escolhidos por Adélia. No caso, os objetos modais nunca estão escritos no texto; eles aparecem apenas como representações pictóricas, como chapéu e o vaso de flores. Os objetos de valor consistem nas personagens criadas por Adélia e apresentadas ao leitor através de ilustrações iconográficas, como a rainha e o rei. A tabela a seguir exibe exemplos de objetos modais e de objetos de valor encontrados no livro:

Quadro 2 - Relação entre Objetos Modais e Objetos de Valor.

\begin{tabular}{|c|c|}
\hline Objetos Modais (Ilustrações) & Objetos de Valor (Personagem) \\
\hline Chapéu & Rainha \\
\hline Boné & Rei \\
\hline Laço & Princesa \\
\hline Chupeta & Príncipe nenê \\
\hline Panela & Cozinheiro \\
\hline Vaso de Flores & Jardineiro \\
\hline Óculos & Vovó \\
\hline
\end{tabular}




\begin{tabular}{|l|l|}
\hline Sapatos & Gato \\
\hline
\end{tabular}

Fonte: Os autores (2018).

O terceiro e mais profundo nível de análise no percurso gerativo de sentido é o fundamental, estruturado sob a forma de uma oposição de termos, sendo um eufórico e outro disfórico. "A sintaxe do nível fundamental abrange duas operações: a negação e a asserção" (FIORIN, 2008, p.23).

A possível oposição semântica de base do livro encontrada é /real/ versus /imaginário/, que se aplica com os elementos da narrativa do texto, sendo, por exemplo, o chapéu um objeto real enquanto a rainha age como objeto imaginário. Da mesma forma, a história vivida por Adélia resulta da afirmação do real enquanto ela escolhe os objetos, da negação do real quando ela adormece e da afirmação do imaginário no momento em que ela encontra tudo havia imaginado para sua brincadeira em seu sonho. Ainda podemos observar a oposição na interação do leitor com o livro, que iniciará sua leitura com o real do texto escrito e partirá para o imaginário do conto de fadas do castelo e da brincadeira vivida por Adélia, podendo até se colocar no lugar da personagem e complementando a história da narrativa.

\title{
4 Plano da Expressão
}

Uma vez feita a análise do Plano do Conteúdo, partimos para o Plano da Expressão. Lúcia Teixeira (2008, p. 304) explica a importância do estudo dos sistemas semi-simbólicos através da metodologia adotada ao dizer que "ler o texto visual, assim, é sempre considerar que o conteúdo se submete às coerções do material plástico e que essa materialidade também significa". Para a continuidade da presente análise, partimos do estudo da semiótica plástica, na qual a leitura de uma imagem partirá da sua expressão e de como ela dá forma ao sentido através de quatro categorias: cromática, eidética, topológica e matérica.

\begin{abstract}
A semiótica plástica, ao prestar atenção à materialidade dos objetos plásticos, recusa a confusão entre o visível e o dizível, evitando uma lexicalização dos textos visuais. Não se trata de decodificar, de interpretar o valor dos signos, nem de descrever habilidades técnicas ou efeitos estéticos. Compreendendo embora a natureza discursiva de toda semiose, a semiótica plástica procura operar com a especificidade material do discurso plástico. Realizável por um jogo de linhas e de cores, de volumes e de luzes sobre um corpo em movimento, ou num espaço construído, o material primeiro dos discursos plásticos é o mundo das qualidades visuais, que tanto pode estar associado ao pictórico como técnica de produção, quanto ao visual como canal sensorial (TEIXEIRA, 2008, p. 305).
\end{abstract}

No livro analisado, é válido ressaltar que o leitor só começará a identificar os objetos das ilustrações quando um de seus sentidos for aguçado: seja pelo tato com as texturas, pelo olfato com os aromas ou pela visão com os contrastes de cores. Por se tratar de um livro acessível a crianças com deficiências visuais e que busca a inclusão nos diversos ambientes, a exploração multissensorial do livro foi aplicada para uma interação mais didática e criativa, possivelmente em um ambiente escolar ou familiar.

Na categoria cromática, é possível identificar muitos contrastes nas matizes de cores das ilustrações e dos planos de fundo, além de combinações como brilhante versus opaco. Como exemplo, é possível observar a aplicação de verniz em áreas que representam o vidro, como vasos de flores, trazendo a ideia de brilhante, enquanto o conteúdo da panela, em outra ilustração, 
remete ao opaco. A maioria das ilustrações são orgânicas e curvilíneas, sendo o castelo o único elemento predominantemente retilíneo na composição eidética.

Imagem 4 - Detalhe do material aplicado em página do livro.

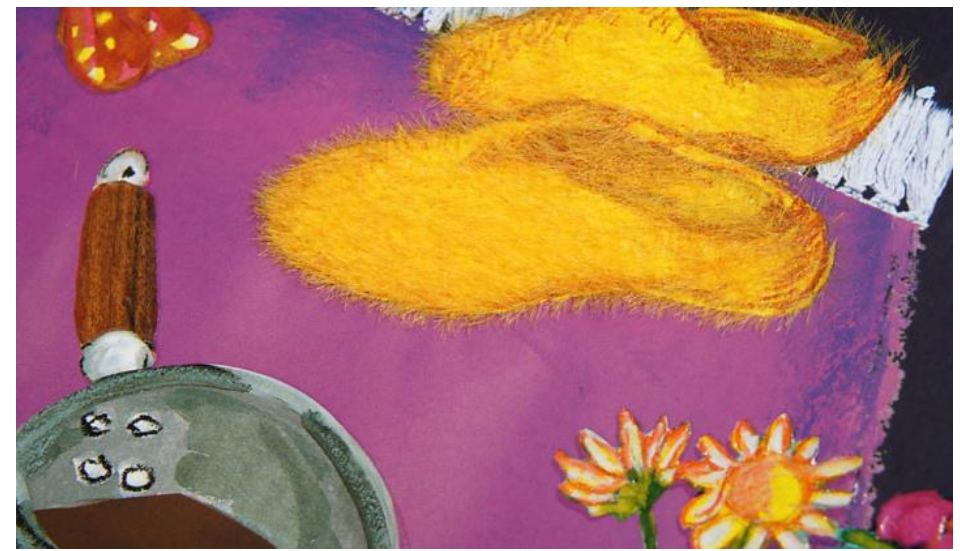

Fonte: <http://www1.folha.uol.com.br/saopaulo/1189436-adelia-sonhadora-une-boa-historia-e-ilustracoes-comtexturas-e-cheiros.shtml>. Acesso em 18 de março de 2018.

Notamos também, a partir da categoria topológica, que os objetos representados nas ilustrações estão centralizados nas primeiras páginas, enquanto são descritos um a um. Uma vez que Adélia os reúne, eles passam a ser periféricos, estando dispersos pela página em escala menor. $\mathrm{Na}$ categoria matéria, observamos que foram aplicados diversos materiais e modos de impressão no livro, desde o braille impresso em serigrafia de verniz, o Braille.BR ${ }^{\circledR}$, apresentando um relevo, de modo que não afunde o papel e não atrapalhe a leitura da escrita alfabética por baixo, até as texturas que reproduzem a sensação tátil real do objeto por ela representado. Na madeira do cabo da panela, por exemplo, vemos suas estrias e irregularidades na pintura e podemos sentir o mesmo na aplicação do verniz. É possível sentir o liso do papel em contraste com o rugoso dos relevos e texturas, sejam elas aplicadas em verniz liso, verniz texturizado ou flocagem. Outro efeito obtido a partir da categoria matérica são os aromas, aplicados em apenas algumas páginas para reforçar o objeto ilustrado, como um cheiro característico de bebês na ilustração da chupeta que representa o príncipe nenê.

Imagem 5 - Detalhe da impressão em Braille.BR sobre a escrita alfabética.

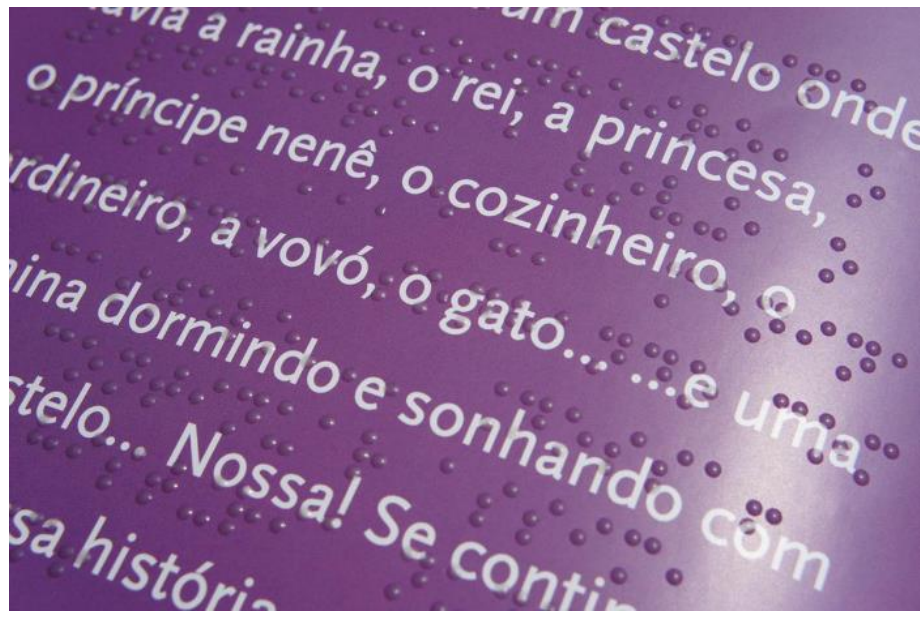


Fonte: <http://www1.folha.uol.com.br/saopaulo/1189436-adelia-sonhadora-une-boa-historia-e-ilustracoes-comtexturas-e-cheiros.shtml>. Acesso em 18 de março de 2018.

\section{Considerações finais}

Realizada a análise, compreendemos que o livro apresenta a seus leitores um modo de interligar a realidade e o imaginário, unindo a narrativa inserida no texto com o universo que circunda o leitor, de forma a destacar um novo modo de reconhecer os objetos presentes na história de Adélia. A partir de estímulos sensoriais, como texturas, aromas e relevos, o leitor é instigado a aprender um diferente sistema de leitura, que vai além da escrita alfabética e do braille e facilita a compreensão do livro e de sua narrativa como um todo. Para isso, observa-se que a teoria semiótica discursiva se mostrou eficiente para este estudo, uma vez que permite a investigação de elementos da narrativa, através do plano do conteúdo, e da materialidade plástica, pelo plano da expressão. Semioticamente, o conteúdo pressupõe a expressão, e vice-versa, sendo ambos complementares para a totalidade de sentido de um texto. A relação entre conteúdo e expressão é fundamental para a experiência proposta pelo livro, considerando a relevância de elementos táteis e olfativos para a acessibilidade do material.

A interação do usuário com o livro é de extrema importância neste objeto e, por isso, é possível identificar duas narrativas em que a análise semiótica aqui apresentada se encaixam: na história de Adélia e na experiência do leitor em relação ao livro. Assim, da mesma maneira em que Adélia atinge a sanção ao alcançar e vivenciar sua brincadeira no sonho, o leitor também a atingirá ao completar a leitura, imaginando além do que está escrito nas páginas e compreendendo todas as figuras apresentadas, finalizando, desta forma, seu percurso de aprendizado. Esta relação entre a narrativa da personagem e o leitor real permite que a criança se identifique com a história contada, aprofundando a experiência.

O corpus analisado se torna, portanto, relevante para a inclusão de crianças com deficiência visual e para a integração social, uma vez que compreende-se que o "argumento mais persuasivo para adotar o Design Inclusivo, assenta no princípio ético que todos os indivíduos têm o mesmo direito fundamental de aceder e utilizar com segurança e conforto o ambiente edificado, bem como os produtos e serviços que nele estão integrados" (SIMÕES e BISPO, 2006, p. 46). Desta forma, o livro permite, além de apresentar novas tecnologias e processos de impressão, como o Braille.BR, a leitura compartilhada de pessoas com deficiência visual e videntes. A inclusão destas crianças demanda por objetos lúdicos, imersivos e participativos como este para a fomentação de diálogos acerca da acessibilidade no universo infantil.

\section{Referências}

FIORIN, José Luiz. Elementos de Análise do Discurso. Editora Contexto, São Paulo, 2008.

Fundação Dorina Nowill para cegos. O que é deficiência. Disponível em: $<$ https://www.fundacaodorina.org.br/a-fundacao/deficiencia-visual/o-que-e-deficiencia/>. Acesso em 18 mar. 2018.

Fundação Dorina Nowill para cegos. O que é visão subnormal ou baixa visão. Disponível em: <https://www.fundacaodorina.org.br/a-fundacao/deficiencia-visual/o-que-e-visao-subnormal-oubaixa-visao/>. Acesso em 18 mar. 2018. 
IBGE, Índice Brasileiro de Geografia e Estatística. Censo Demográfico 2000. 2000. Disponível em: <http://www.ibge.gov.br/home/presidencia/noticias/20122002censo.shtm>. Acesso em: 03 jun. 2017.

LINDEN, Sophie van Der (Org.). Para Ler o Livro Ilustrado. São Paulo: Cosac Naify, 2011.

LINS, Guto. Livro infantil? Projeto gráfico, metodologia, subjetividade. Editora Rosari, São Paulo, 2002.

SIMÕES, Jorge Falcato; BISPO, Renato. Design Inclusivo: Acessibilidade e Usabilidade em

Produtos, Serviços e Ambientes. 2ª edição. Lisboa: Centro Português de Design, 2006, 84p.

TEIXEIRA, Lucia. Leitura de textos visuais: princípios metodológicos. In: BASTOS, Neusa Barbosa (org.). Língua portuguesa: lusofonia - memória e diversidade cultural. São Paulo: EDUC, 2008. p.299-306

WG Produto. Coleção Adélia: inovações para um mundo melhor. Disponível em: <https://www.wgproduto.com.br/colecaoadelia>. Acesso em 18 mar. 2018.

WG Produto. O novo braille. Disponível em: <https://www.wgproduto.com.br/braillebr>. Acesso em 18 mar. 2018. 